Augenärztliche Technik.

Von Prof. Abelsdorff und Dr. K. Steindorff in Berlin. $\mathrm{X}$.

Kleine chirurgische Maßnahmen.

Von Dr. Kurt Steindorff.

I. Entfernung von Bindehaut-Fremdkörpern.

Wie man sich "die Innenfläche des Lides (Lidbindehaut und Uebergangsfalten) durch Umstülpen sichtbar macht, wurde von $A b e l s d$ orf $f$ in dem 2. dieser Aufsätze und nochmals von mir bei Besprechung der Technik des Pinselns der Bindehaut geschildert. Es sei wiederholt darauf hingewiesen, da $B$ man sich vor Verwendung unsauberer und spitzer Instrumente, auch vor spitz zugeschnittenen und langen Fingernägeln zu hüten hat, auch jeden starken Druck auf den Augapfel vermeiden muß, wenn man nicht Gefahr laufen will, schweren Schaden anzurichten. 
Ehe man daran geht, die Lider umzukehren, empfiehlt es sich, nachzusehen, ob gröbere Staubpartikelchen auf der Haut in der Umgebung des Auges liegen, und sie zu beseitigen. Denn beim Ektropionieren kommt es leicht vor, daß schon durch den Handgriff ein im Bindehautsack liegender Fremdkörper mit dem Tränenstrom herausbefördert wird, sodaß man ihn weder auf der Lidbindehaut noch in den Nischen der Uebergangsfalten findet, wohl aber auf der Haut des Unterlides. Aber nur, wenn man vorher festgestellt hat, daß vor dem Ektropionieren auf der Lidhaut nichts gelegen hat, kann man ein dort jetzt gefundenes Partikelchen als den aus dem Bindehautsack herausgeschwemmten Attentäter ansprechen.

Findet man ihn aber noch auf der Bindehaut, so wischt man ihn leicht mit einem kleinen angefeuchteten Wattebausch ab. Man versäume nie nachzusehen, ob durch den Fremdkörper das Epithel der Hornhaut verletzt wurde, und verbinde in diesem Falle das Auge. Oft hat der Kranke nach Entfernung noch dieselben Beschwerden, Stechen und Schmerzen, wie zuvor, zumal wenn das Auge durch Reiben oder unzweckmäBige und daher erfolglose Extraktionsversuche gereizt wurde. Darum ist es immer gut, wenn man dem Patienten das als schwarzes Pünktchen auf der Watte sichtbare Stäubchen als Beweisobjekt vorzeigt. Die etwa noch vorhandenén Schmerzen werden durch Einträufeln eines Tropfens Cocain. mur. $2 \%$ ig bald beseitigt.

Nur wenn $\mathrm{Kalk}$, besonders ungelöschter, in den Bindehautsack gelangt, droht dem Auge Gefahr, weil er nicht nur thermisch und mechanisch, sondern vor allem chemisch auf die Gewebe einwirkt: Bindehaut und Hornhaut werden verätzt. So schnell wie möglich müssen möglichst alle im Bindehautsack liegenden Partikelchen nach vorheriger Kokainisierung mit einem feuchten Wattebausch oder, wenn sie festhaften, mit einer Fremdkörpernadel oder einem kleinen scharfen Löffel entfernt werden. AuBerdem ist der Bindehautsack ausgiebigst mit reinem Wasser gründlich auszuspülen, wozu man sich einer Undine oder eines gewöhnlichen Irrigators bedient oder, wenn diese nicht gleich zur $H$ and sind, vollgesogener Wattebäusche, die man über die vollkommen umgestülpten Lider und Uebergangsfalten ausdrückt. Danach streicht man mit einem geknöpften Glasstäbchen reichlich Salbe (3\%ige Borvaseline) ein, um so ein Verkleben der verätzten Bindehautstellen untereinander und mit der Hornhaut zu verhüten, und legt einen Salbenverband an. Das Einstreichen der Salbe und Verbinden soll mehrmals am Tage wiederholt werden. Ist die Hornhaut an der Verätzung beteiligt, so träufele man von vornherein Atropin (1\% ig) ein. In schwereren Fällen ist klinische Aufnahme und fachärztliche Behandlung unbedingt anzurater.

\section{Entfernung von Hornhaut-Fremdkörpern.}

Lose auf der Hornhautoberfläche haftende Fremdkörper versuche man nach gründlicher Kokainisierung unter guter seitlicher Beleuch. tung (vgl. Abschnitt II) mit einem feuchten Wattetupfer herauszuwischen. Zeigefinger und Daumen der linken Hand ziehen die Lider auseinander und üben einen leichten Druck auf den Augapfel aus, um ihn zu fixieren. Gelingt die Entfernung des Fremdkörpers nicht, so - bediene man sich einer vorher ausgekochten (oder ausgeglühten Platin-l ridium-) Fremdkörpernadel. Man stellt sich vor den auf einem Stuhl sitzenden Kranken, der den leicht nach rückwärts gebeugten Kopf gegen die Brust eines Gehilfen oder eine Kopfstütze (Wand) lehnt und geradeaus blickt. Mit dem Mittel-, Ring- und kleinen Finger der linken Hand zieht man das Oberlid empor wobei man einen geringen Druck auf den Augapfel ausübt, um ihn möglichst ruhigzustellen. Handgelenk und Unterarm ruhen sanft auf dem Kopf des Patienten und helfen dadurch, ihn zu fixieren. Daumen und Zeigefinger halten eine mit Fassung und Griff versehene Linse von + 20.0 D., die das Licht einer seitlich vor dem Kranken'stehenden künstlichen Lichtquelle scharf auf die Stelle konzentriert, wo der Fremdkörper sitzt. Mit der rechten $\mathrm{Hand}$ faßt man die Nadel so, daB das Endglied des Daumens auf der einen Seite des Griffs liegt, die Endglieder des Zeige- und Mittelfingers auf der andern Seite. Der 4. Finger ruht neben dem Mittelfinger, während die Spitze des kleinen Fingers das untere Lid herabzieht und sich dabei auf den knöchernen unteren Augenhöhlenrand stützt. Man geht nun mit der Nadel, die man nicht steil aufsetzen soll, an den Fremdkörper von hinten heran und gräbt ihn gewissermaßen aus seinem Bett heraus, ohne das umgebende Hornhautepithel unnötig abzuschaben. Bei seitlicher Beleuchtung unter Zuhilfenahme einer sog. Kugellupe (Leitz; Zeiß) sieht man nach, ob, wenn es sich um Eisensplitterchen handelt, noch Rostpartikelchen zurückgeblieben sind. Da sie das Auge reizen, ist für ihre möglichst vollständige Entfernung zu sorgen, die nur dann unterbleiben soll, wenn der Rost so tief im Gewebe sitzt, daB man bei seiner Entfernung eine Perforation befürchten muß. Besonders bei zentral sitzenden Splittern ist in dieser Hinsicht mit gröBter Vorsicht zu verfahren, weil hier die Dicke der Hornhaut nur ungefähr $1 / 2 \mathrm{~mm}$ beträgt. Der Operateur kann den Eingriff auch hinter dem Stuhl des Patienten stehend und ohne lokale Beleuchtung vornehmen, indem er dessen Kopf gegen seine Brust lehnt, mit Daumen und Zeigefinger der linken Hand die Lider auseinanderzieht und den Fremdkörper mit der von der rechten Hạd geführten Nadel heraushebelt.
Wenn der Fremdkörper schon länger haftete und von einem grau infiltrierten Hof umgeben ist, wenn stärkere ziliare Reizung des Auges auf Komplikationen seitens der Iris hindeutet, so ist nach der Entfernung des Splitters ein Tropfen Atropin. sulf. neutr. (1\% ig) einzuträufeln. In jedem Falle von Hornhautfremdkörper ist zur Verhütung sekundärer Infektion das verletzte Auge so lange zu verbinden, bis der Hornhautdefekt verheilt ist, also bis das Epithel an der Stelle, wo der Splitter saB, wieder spiegelt bzw. durch Fluoreszin nicht mehr grün verfärbt wird.

\section{Eröffnung yon Gerstenkörnern.}

Das Hordeolum externum ist eine akute eitrige Entzündung der Haarbalgdrüsen einer Wimper. Oft sieht man aus dem kleinen gelben Abszeßchen die Wimper hervorragen. Man epiliert sie mit einer Zilienpinzette, Abbildung: $\mathrm{S}$ chwalbe, Technik, 1097, S. 333, indem man sie zwischen die Branchen des Instruments faBt und mit einem kurzen Ruck herauszieht. An ihrer Wurzel haftet ein kleines Eiterflöckchen, und aus dem so eröffneten Abszeß quillt ein Eitertröpfchen und wird mit einem in eine antiseptische Flüssigkeit, z. B. in Hydrarg. oxycyan. $0,2: 1000,0$ getauchten Wattebausch vorsichtig abgetupft. Zur Eröffnung größerer Abszesse muß man sich eines kleinen spitzen Messerchens bedienen.

Beim Hordeolum internum handelt es sich um eine akute, durch Eindringen von Eitererregern (Staphylococcus aureus) verursachte Entzündung einer Meibomschen Drüse. Bis zur Abszeßbildung sind heiße Umschläge angezeigt, sobald aber der Eiter unter der Bindehaut gelb durchschimmert, mache man von der Bindehautseite einen senkrecht verlaufenden Einschnitt. Die senkrecht zum Lidrande verlaufende Schnittrichtung ist zu wählen, um den Lidknorpel und die in ihm eingebetteten Talgdrüsen zu schonen.

Sowohl nach der Eröffnung des Hordeolum externum wie nach der des Hordeolum internum ist die weitere Entfernung von Eiter durch stärkeres Drücken ein grober Fehler.

\section{Eröffnung des Hagelkornes.}

Das $\mathrm{Hagelk}$ orn ( $\mathrm{Ch}$ alazion) ist eine chronische Granulationsgeschwulst einer Meibomschen Drüse. Sie wölbt die Lidhaut, mit der sie nicht verwachsen ist, bis zu Erbsengröße vor, die Bindehaut ist über ihr graurötlich verfärbt. Da die spontane Resorption sehr selten ist, die Geschwulst vielmehr nach längerem Bestehen aufbricht und den Boden für' pilzförmig hervorbrechende Granulationswucherungen abgibt, ist die Eröffnung mit einem spitzen Messerchen von der Bindehaut und nachheriges Auskratzen mit einem kleinen scharfen Löffel zu empfehlen. Man macht die Bindehaut durch Einträufelung von Kokain (2\% ig) mit Suprarenin (1\% ; gtts. V: $10,0 \mathrm{Aq}$. dest.) unempfindlich, kann auch mit einer kleinen Rekordspritze $(1,0 \mathrm{ccm})$ einige Tropfen dieser Lösung um die kleine Geschwulst herum in das Gewebe einspritzen. Dann faßt man das umgestülpte Lid zwischen Daumen und Zeigefinger der linken Hand, was das lästige Einlegen einer Klemm- (sog. Chalazion-) Pinzette überflüssig macht. Man eröffnet die Geschwulst durch einen kleinen kreuzförmigen Schinitt, worauf die gelatinösen, häufig schon eitrig eingeschmolzenen Geschwulstmassen austreten, und kratzt die noch haftenden mi: dem Löffelchen gründlich aus. Infolge des Austritts von Blut in die Wundhöhle bleibt da, wo das Hagelkorn saB, eine kleine Anschwellung zurück, die aber nach wenigen Tagen verschwindet. Kommt es zu einem Rückfall, so muB die Ausschälung mit der Wandung von der Hautseite aus vorgenommen werden, die wohl besser dem Facharzt überlassen bleibt, ebenso wie die Entfernung sehr großer Hagelkörner von außen her oder die z. B. von Eversbusch empfohlene galvanokaustische Zerstörung der kleinen Tumoren. 